\title{
Comparative Docking analysis of rational drugs against COVID- 19 Main Protease
}

\author{
Lalit R. Samant ${ }^{1^{*}}$, Vyomesh R. K. Javle ${ }^{2}$ \\ ${ }^{1}$ B. J. Wadia Hospital for Children, A.D. Marg, Parel, MH, India-12. \\ ${ }^{2}$ Department of Bioinformatics, Patkar-Varde College, Mumbai,MH, India-04.
}

\begin{abstract}
:-
COVID-19, a new strain of coronavirus (CoV), was identified in Wuhan, China, in 2019. No specific therapies are available, and investigations regarding COVID-19 treatment are lacking. Crystallised COVID-19 main protease (Mpro), which is a potential drug target. The present study aimed to assess drugs found in literature as potential COVID-19 Mpro inhibitors, using a molecular docking study. Molecular docking was performed using Autodock 4.2, with the Lamarckian Genetic Algorithm, to analyse the probability of docking. The docking was cross-validated using Swiss Dock. COVID-19 Mpro was docked with several compounds, and docking was analysed by Biovia Discovery Studio 2020. Quinine and hydroxychloroquine were used as standards for comparison. The binding energies obtained from the docking of 6LU7, 2GTB with screened drugs viz., Quinine, Artesunate, Clotrimazol, Artemether, Quercetin, Mefloquine, ciprofloxacin, clindamycin, cipargamin, SJ-733 were in between -7.0 to $-9.6 \mathrm{kcal} / \mathrm{mol}$. On consideration of similar binding energy obtained from Autodock vina and SWISSDock and interaction residue pattern specifically (GLU 166,CYS 145, CYS44 and MET 49 residue) for SJ-733 \& JPC-3210 may represent potential treatment options, and appeared to have the best potential to act as COVID-19 Mpro inhibitors. However, further research is necessary to investigate their potential medicinal use against $\mathrm{CoV}$.
\end{abstract}

Keywords: Drugs, Docking, Protease, Corona Virus, Autodock

Introduction:-

Coronaviruses (CoVs) are an etiologic agent of severe infections in both humans and animals, which may cause disorder not only within the respiratory tract but also within the alimentary canal and systemically. Previous studies of CoVs have reported that CoVs can infect certain species of animals, including mammals, avian species, and reptiles. Consistent with the present situational report from WHO, released on April 7, 2020, 12,79,722 COVID19 cases are confirmed globally, China, the number of confirmed cases reached 83,071, including 66 new cases, and 3340 deaths. Outside of China, 395 cases were confirmed in 150 countries, (1). Currently, no specific therapies for COVID-19 are available, and investigations regarding the treatment of COVID-19 are lacking(2). The current line of treatment includes antimalarial drug (3). However, the measures that are implemented 
remain limited to preventive and supportive therapies designed to stop further complications and organ damage (2). Researchers have successfully crystallised the most protease (Mpro)/chymotrypsin-like protease (3CLpro) from COVID-19, which has been structured and repositioned within the Protein Data Bank (PDB) and is accessible by the general public. This protease represents a possible target for the inhibition of $\mathrm{CoV}$ replication (4). The drugs were selected from drug bank on the basis of the literature survey. The findings of this study will provide other researchers with opportunities to spot the proper drug to combat COVID19.

Methods

Macromolecules/ Proteins:

The 3-dimensional (3D) structures were obtained from PubChem and Drugbank (https://pubchem.ncbi.nlm.nih.gov/), in .sdf format. PubChem is a chemical substance and biological activities repository consisting of three databases, including substance, compound, and bioassay databases (5).

COVID-19 3clpro/Mpro (PDB ID: 6LU7) and 3clpro/Mpro (PDB ID: 2GTB) (4) structures were obtained from PDB (https://www.rcsb.org/), in .pdb format. PDB is an archive for the crystal structures of biological macromolecules, worldwide. The 6LU7 protein contains two chains, A and B, which form a homodimer. Chain A was used for macromolecule preparation. The native ligand for 6LU7 is n-[(5-methylisoxazol-3yl)carbonyl]alanyl-1-valyln 1 -((1r,2z)-4-(benzyloxy)-4-oxo-1- \{[(3r)-2-oxopyrrolidin-3yl]methyl $\}$ but-2-enyl)-1leucinamide whearas of 2 GTB is aza-peptide epoxide.

\section{Drug likeness}

Drug-like properties were calculated using Lipinski's rule of five(6), which proposes that molecules with poor permeation and oral absorption have molecular weights $>500, \mathrm{C} \log \mathrm{P}>$ 5 , more than 5 hydrogen-bond donors, and more than 10 acceptor groups $(7,8)$ Adherence with Lipinski's rule of five as calculated using SWISSADME prediction (http://www.swissadme.ch/).

Active Site identification

The amino acids in the active site of a protein were determined using meta pocket (https://projects.biotec.tu-dresden.de/metapocket/) accessed on $6^{\text {th }}$ April,2020 and Biovia Discovery studio client 2020 (Dassault Systèmes BIOVIA, Discovery Studio Modeling Environment, Release 2017, San Diego: Dassault Systèmes, 2016). 
Molecular docking

Ligand optimisation was performed by marvin sketch and saved in .mol2 format. Autodock version 4.2 used for protein optimisation, by removing water and other atoms, and then adding a polar hydrogen group. Autodock 4.2 was supported by Autodock tools, MGL tools, and Rasmol. Autogrid then determined the native ligand position on the binding site by arranging the grid coordinates (X, Y, and Z). Ligand tethering of the protein was performed by regulating the genetic algorithm (GA) parameters, using 10 runs of the GA criteria $(9,10)$.

The drugs which shows better non covalent interaction and binding energy as compared to standard drugs, quinine and hydroxychloroquine were selected further for cross validation on swiss dock work bench accessed on $8^{\text {th }}$ April,2020 (11). The docking analyses was performed by Biovia Discovery studio client 2020(Dassault Systèmes BIOVIA, Discovery Studio Modeling Environment, Release 2017, San Diego: Dassault Systèmes, 2016).

Results :

The Lipinski filter data is added as supplementary material.

Table 1: Binding energy and amino acid interaction table between compounds and 6LU7

\begin{tabular}{|c|c|c|c|c|c|c|}
\hline $\begin{array}{l}\text { Sr. } \\
\text { No. }\end{array}$ & Drug Name & $\begin{array}{l}\text { Chemical } \\
\text { formula }\end{array}$ & $\begin{array}{l}\text { Autodock } \\
(\mathrm{KJ} / \mathrm{mol})\end{array}$ & Interaction & $\begin{array}{l}\text { Swiss } \\
\text { Dock } \\
(\mathrm{KJ} / \mathrm{mol})\end{array}$ & Interaction \\
\hline 1 & SJ-733 & $\mathrm{C}_{24} \mathrm{H}_{16} \mathrm{~F}_{4} \mathrm{~N}_{4} \mathrm{O}_{2}$ & -8.7 & $\begin{array}{l}\text { 1] Electrostatic } \\
\text { Interaction: } \\
\text { GLU166, } \\
\text { MET165,ASP187, } \\
\text { CYS145, HIS164 } \\
\text { 2]Van der waals } \\
\text { interaction:NIL } \\
\end{array}$ & -8.4 & $\begin{array}{l}\text { 1] Electrostatic } \\
\text { Interaction:GLU166, MET49, } \\
\text { ASN142 } \\
\text { 2]Van der waals interaction: } \\
\text { PHE140 }\end{array}$ \\
\hline 2 & Tafenoquine & $\mathrm{C}_{24} \mathrm{H}_{28} \mathrm{~F}_{3} \mathrm{~N}_{3} \mathrm{O}_{3}$ & -8.3 & $\begin{array}{l}\text { 1] Electrostatic } \\
\text { Interaction: } \\
\text { THR190, GLN192 } \\
\text { 2]Van der waals } \\
\text { interaction: } \\
\text { PRO168,LEY141, } \\
\text { ARG188 } \\
\end{array}$ & -9.0 & $\begin{array}{l}\text { 1] Electrostatic Interaction: } \\
\text { HIS164, ASN142, THR26, } \\
\text { MET165 } \\
\text { 2]Van der waals interaction: } \\
\text { LEu141, }\end{array}$ \\
\hline 3 & Cipargamin & $\mathrm{C}_{19} \mathrm{H}_{14} \mathrm{Cl}_{2} \mathrm{FN}_{3} \mathrm{O}$ & -8.2 & $\begin{array}{l}\text { 1] Electrostatic } \\
\text { Interaction:HIS41, } \\
\text { HIS164, CYS145, } \\
\text { THR190 } \\
\text { 2]Van der waals } \\
\text { interaction: } \\
\text { PRO168, MET165 }\end{array}$ & -7.8 & $\begin{array}{l}\text { 1] Electrostatic } \\
\text { Interaction:GLY143, } \\
\text { LEU141, SER144, CYS145, } \\
\text { MET165 } \\
\text { 2]Van der waals } \\
\text { interaction:HIS172 }\end{array}$ \\
\hline 4 & Clotrimazol & $\mathrm{C}_{22} \mathrm{H}_{17} \mathrm{ClN}_{2}$ & -8.2 & $\begin{array}{l}\text { 1] Electrostatic } \\
\text { Interaction:NIL } \\
\text { 2]Van der waals } \\
\text { interaction:ARG188, } \\
\text { HIS41, } \\
\text { CYS145,MET165 }\end{array}$ & -7.6 & $\begin{array}{l}\text { 1] Electrostatic } \\
\text { Interaction:MET165,ASN142, } \\
\text { GLY143 2]Van der waals } \\
\text { interaction:MET49,CYS145, } \\
\text { LEU141 }\end{array}$ \\
\hline 5 & Mefloquine & $\mathrm{C}_{17} \mathrm{H}_{16} \mathrm{~F}_{6} \mathrm{~N}_{2} \mathrm{O}$ & -8.1 & $\begin{array}{l}\text { 1] Electrostatic } \\
\text { Interaction: HIS41, } \\
\text { TYR54, CYS145, } \\
\text { HIS164, MET49 } \\
\text { 2]Van der waals } \\
\text { interaction: NIL } \\
\end{array}$ & -9.3 & $\begin{array}{l}\text { 1] Electrostatic Interaction: } \\
\text { ASP187, ARG188, MET49, } \\
\text { MET165, GLU166, } \\
\text { ASN142(bumps) 2]Van der } \\
\text { waals interaction: } \\
\text { LEU141(Bumps) }\end{array}$ \\
\hline 6 & Artesunate & $\mathrm{C}_{19} \mathrm{H}_{28} \mathrm{O}_{8}$ & -7.9 & $\begin{array}{l}\text { 1] Electrostatic } \\
\text { Interaction: }\end{array}$ & -8.6 & $\begin{array}{l}\text { 1] Electrostatic Interaction: } \\
\text { PHE140, GLY143 2]Van der }\end{array}$ \\
\hline
\end{tabular}




\begin{tabular}{|c|c|c|c|c|c|c|}
\hline & & & & $\begin{array}{l}\text { GLU166, THR26 } \\
\text { 2]Van der waals } \\
\text { interaction: HIS41, } \\
\text { MET49, MET165 }\end{array}$ & & waals interaction: LEU27 \\
\hline 7 & Artemether & $\mathrm{C}_{16} \mathrm{H}_{26} \mathrm{O}_{5}$ & -7.7 & $\begin{array}{l}\text { 1] Electrostatic } \\
\text { Interaction:ASP187, } \\
\text { HIS41, CYS145 } \\
\text { 2]Van der waals } \\
\text { interaction: } \\
\text { MET165, } \\
\end{array}$ & -7.8 & $\begin{array}{l}\text { 1] Electrostatic Interaction: } \\
\text { LEU141, CYS145 2]Van der } \\
\text { waals interaction: MET49, } \\
\text { MET165 }\end{array}$ \\
\hline 8 & JPC-3210 & $\mathrm{C}_{21} \mathrm{H}_{26} \mathrm{~F}_{4} \mathrm{~N}_{2} \mathrm{O}$ & -7.6 & $\begin{array}{l}\text { 1] Electrostatic } \\
\text { Interaction: } \\
\text { GLU166,CYS145, } \\
\text { THR26,THR24, } \\
\text { GLY143 2]Van der } \\
\text { waals interaction: } \\
\text { MET49,MET165, } \\
\text { HIS41, THR25 }\end{array}$ & -8.6 & $\begin{array}{l}\text { 1] Electrostatic } \\
\text { Interaction:MET49, MET165, } \\
\text { HIS41, GLU166, ARG188, } \\
\text { ASP187 2]Van der waals } \\
\text { interaction: NIL }\end{array}$ \\
\hline 9 & Artenimol & $\mathrm{C}_{15} \mathrm{H}_{24} \mathrm{O}_{5}$ & -7.6 & $\begin{array}{l}\text { 1] Electrostatic } \\
\text { Interaction: HIS41 } \\
\text { 2]Van der waals } \\
\text { interaction: MET165 }\end{array}$ & -7.4 & $\begin{array}{l}\text { 1] Electrostatic } \\
\text { Interaction:CYS145, GLY143 } \\
\text { 2]Van der waals } \\
\text { interaction:MET165, MET49 }\end{array}$ \\
\hline 10 & Quercetin & $\mathrm{C}_{15} \mathrm{H}_{10} \mathrm{O}_{7}$ & -7.6 & $\begin{array}{l}\text { 1] Electrostatic } \\
\text { Interaction:THR190, } \\
\text { ARG188, GLN192, } \\
\text { GLU166, MET165, } \\
\text { HIS163, SER144, } \\
\text { CYS145, GLY143, } \\
\text { LEU141 2]Van der } \\
\text { waals } \\
\text { interaction:NIL }\end{array}$ & -7.2 & $\begin{array}{l}\text { 1] Electrostatic Interaction: } \\
\text { GLU166, MET165,, MET49, } \\
\text { GLY143, CYS145 2]Van der } \\
\text { waals interaction:ASN142 }\end{array}$ \\
\hline 11 & Ciprofloxacin & $\mathrm{C}_{17} \mathrm{H}_{18} \mathrm{FN}_{3} \mathrm{O}_{3}$ & -7.5 & $\begin{array}{l}\text { 1] Electrostatic } \\
\text { Interaction:GLY143, } \\
\text { SER144, CYS145, } \\
\text { GLU166, THR190, } \\
\text { 2]Van der waals } \\
\text { interaction:ARG188, } \\
\text { HIS41, MET49 }\end{array}$ & -9.6 & $\begin{array}{l}\text { 1] Electrostatic Interaction: } \\
\text { ARG188, ASP187, MET49, } \\
\text { GLN189, MET165, GLU166, } \\
\text { CYS145, PHE140, } \\
\text { LEU141(Bumps) 2]Van der } \\
\text { waals interaction:NIL }\end{array}$ \\
\hline 12 & Artemisinin & $\mathrm{C}_{15} \mathrm{H}_{22} \mathrm{O}_{5}$ & -7.5 & $\begin{array}{l}\text { 1] Electrostatic } \\
\text { Interaction: HIS41 } \\
\text { (bumps_H bonds), } \\
\text { GLN189 2]Van der } \\
\text { waals } \\
\text { interaction:MET165 } \\
\end{array}$ & -7.3 & $\begin{array}{l}\text { 1] Electrostatic Interaction: } \\
\text { MET49, GLY143, MET165, } \\
\text { CYS145, 2]Van der waals } \\
\text { interaction: LEU27 }\end{array}$ \\
\hline 13 & Clindamycin & $\mathrm{C}_{18} \mathrm{H}_{33} \mathrm{ClN}_{2} \mathrm{O}_{5} \mathrm{~S}$ & -7.4 & $\begin{array}{l}\text { 1] Electrostatic } \\
\text { Interaction: } \\
\text { GLY143, CYS145, } \\
\text { GLU166, } \\
\text { THR190,MET165 } \\
\text { 2]Van der waals } \\
\text { interaction:HIS41, } \\
\text { MET49,PRO168 }\end{array}$ & -8.7 & $\begin{array}{l}\text { 1] Electrostatic } \\
\text { Interaction:THR24,MET49, } \\
\text { THR26, LEU27, GLY143, } \\
\text { 2]Van der waals } \\
\text { interaction:HIS164 }\end{array}$ \\
\hline 14 & Quinine & $\mathrm{C}_{20} \mathrm{H}_{24} \mathrm{~N}_{2} \mathrm{O}_{2}$ & -7.3 & $\begin{array}{l}\text { 1] Electrostatic } \\
\text { Interaction: } \\
\text { SER144, CYS145, } \\
\text { GLU166, HIS41 } \\
\text { 2]Van der waals } \\
\text { interaction: HIS163 }\end{array}$ & -8.3 & $\begin{array}{l}\text { 1] Electrostatic Interaction: } \\
\text { GLU166, GLN189, } \\
\text { ASN142(red) 2]Van der } \\
\text { waals interaction:MET49 }\end{array}$ \\
\hline
\end{tabular}

Table 2: Binding energy and amino acid interaction table between compounds and 2GTB

\begin{tabular}{|c|c|c|c|c|c|c|}
\hline $\begin{array}{l}\text { Sr. } \\
\text { No. }\end{array}$ & $\begin{array}{l}\text { Drug } \\
\text { Name }\end{array}$ & $\begin{array}{l}\text { Chemical } \\
\text { formula }\end{array}$ & $\begin{array}{l}\text { Autodock } \\
(\mathrm{KJ} / \mathrm{mol})\end{array}$ & Interaction & $\begin{array}{l}\text { Swiss } \\
\text { Dock } \\
(\mathrm{KJ} / \mathrm{mol})\end{array}$ & Interaction \\
\hline 1 & SJ-733 & $\mathrm{C}_{24} \mathrm{H}_{16} \mathrm{~F}_{4} \mathrm{~N}_{4} \mathrm{O}_{2}$ & -8.3 & $\begin{array}{l}\text { 1] Electrostatic } \\
\text { Interaction:GLU166 } \\
\text {, THR190, ASN142 } \\
\text { 2]Van der Waals } \\
\text { Interaction:MET165 } \\
\text { LEU167, } \\
\text { ALA191,PRO168 }\end{array}$ & -8.9 & $\begin{array}{lr}1] & \text { Electrostatic } \\
\text { Interaction:HIS41, MET49, } \\
\text { GLU166 2]Van der Waals } \\
\text { Interaction:CYS145, ASP187 }\end{array}$ \\
\hline 2 & $\begin{array}{l}\text { Tafenoquin } \\
\text { e }\end{array}$ & $\mathrm{C}_{24} \mathrm{H}_{28} \mathrm{~F}_{3} \mathrm{~N}_{3} \mathrm{O}_{3}$ & -7.3 & $\begin{array}{l}\text { 1] Electrostatic } \\
\text { Interaction:GLN192 }\end{array}$ & -9.0 & $\begin{array}{l}\text { 1] Electrostatic } \\
\text { Interaction:CYS145, }\end{array}$ \\
\hline
\end{tabular}




\begin{tabular}{|c|c|c|c|c|c|c|}
\hline & & & & $\begin{array}{l}\text { HIS163, GLU166 } \\
\text { 2]Van der Waals } \\
\text { Interaction:LEU141, } \\
\text { PRO168, MET165 }\end{array}$ & & $\begin{array}{l}\text { ASN142, THR26 2]Van der } \\
\text { Waals Interaction: MET49 }\end{array}$ \\
\hline 3 & $\begin{array}{l}\text { Cipargami } \\
\mathrm{n}\end{array}$ & $\mathrm{C}_{19} \mathrm{H}_{14} \mathrm{Cl}_{2} \mathrm{FN}_{3} \mathrm{O}$ & -7.0 & $\begin{array}{l}\text { 1] Electrostatic } \\
\text { Interaction: } \\
\text { GLN192, 2]Van der } \\
\text { Waals } \\
\text { Interaction:MET165 } \\
\text {, LEU167, PRO168 }\end{array}$ & -7.8 & $\begin{array}{l}\text { 1] Electrostatic Interaction: } \\
\text { HIS41, MET165, ASN142, } \\
\text { MET49, GLY143 2]Van der } \\
\text { Waals Interaction:LEU141, }\end{array}$ \\
\hline 4 & $\begin{array}{l}\text { Clotrimazo } \\
1\end{array}$ & $\mathrm{C}_{22} \mathrm{H}_{17} \mathrm{ClN}_{2}$ & -7.2 & $\begin{array}{lr}\text { 1] Electrostatic } \\
\text { Interaction: NIL } \\
\text { 2]Van der Waals } \\
\text { Interaction: } \\
\text { GLN189, GLU166, } \\
\text { LEU167, PRO168, } \\
\text { MET165 }\end{array}$ & -7.6 & $\begin{array}{l}\text { 1] Electrostatic Interaction: } \\
\text { GLY143 CYS145 2]Van der } \\
\text { Waals } \\
\text { Interaction:MET49,HIS164 }\end{array}$ \\
\hline 5 & $\begin{array}{l}\text { Mefloquin } \\
\mathrm{e}\end{array}$ & $\mathrm{C}_{17} \mathrm{H}_{16} \mathrm{~F}_{6} \mathrm{~N}_{2} \mathrm{O}$ & -6.3 & $\begin{array}{l}\text { 1] Electrostatic } \\
\text { Interaction: } \\
\text { LEU167, GLU166 } \\
\text { 2]Van der Waals } \\
\text { Interaction: } \\
\text { MET165, PRO168, }\end{array}$ & -8.0 & $\begin{array}{l}\text { 1] Electrostatic } \\
\text { Interaction:MET49, } \\
\text { HIS41,HIS164, MET165 } \\
\text { 2]Van der Waals Interaction: } \\
\text { NIL }\end{array}$ \\
\hline 6 & Artesunate & $\mathrm{C}_{19} \mathrm{H}_{28} \mathrm{O}_{8}$ & -7.7 & $\begin{array}{l}\text { 1] Electrostatic } \\
\text { Interaction:GLY143 } \\
\text {, GLU166, PRO168, } \\
\text { MET165 2]Van der } \\
\text { Waals Interaction: } \\
\text { NIL }\end{array}$ & -8.1 & $\begin{array}{l}\text { 1] Electrostatic Interaction: } \\
\text { GLU166, ASP187, MET165 } \\
\text { 2]Van der Waals Interaction: } \\
\text { CYS145 }\end{array}$ \\
\hline 7 & Artemether & $\mathrm{C}_{16} \mathrm{H}_{26} \mathrm{O}_{5}$ & -7.3 & $\begin{array}{l}\text { 1] Electrostatic } \\
\text { Interaction: } \\
\text { GLU166 2]Van der } \\
\text { Waals Interaction: } \\
\text { CYS145, MET49, } \\
\text { HIS41 }\end{array}$ & -7.6 & $\begin{array}{l}\text { 1] Electrostatic Interaction: } \\
\text { MET165, GLU166 2]Van } \\
\text { der Waals Interaction: } \\
\text { CYS145 }\end{array}$ \\
\hline 8 & JPC-3210 & $\mathrm{C}_{21} \mathrm{H}_{26} \mathrm{~F}_{4} \mathrm{~N}_{2} \mathrm{O}$ & -7.6 & $\begin{array}{l}\text { 1] Electrostatic } \\
\text { Interaction:HIS163, } \\
\text { GLU166, CYS145, } \\
\text { PHE140, LEU141 } \\
\text { 2]Van der Waals } \\
\text { Interaction:MET49, } \\
\text { HIS41, CYS44 }\end{array}$ & -8.3 & $\begin{array}{l}\text { 1] Electrostatic } \\
\text { Interaction:CYS44, HIS41, } \\
\text { ASP187, MET49, MET165, } \\
\text { GLU166, ARG188 2]Van } \\
\text { der Waals Interaction: NIL }\end{array}$ \\
\hline 9 & Artenimol & $\mathrm{C}_{15} \mathrm{H}_{24} \mathrm{O}_{5}$ & -7.6 & $\begin{array}{l}\text { 1] Electrostatic } \\
\text { Interaction: } \\
\text { GLU166, MET165 } \\
\text { 2]Van der Waals } \\
\text { Interaction: } \\
\text { HIS41,CYS145, }\end{array}$ & -7.5 & $\begin{array}{l}\text { 1] Electrostatic Interaction: } \\
\text { MET49, GLU166 2]Van der } \\
\text { Waals Interaction:CYS145 }\end{array}$ \\
\hline 10 & Quercetin & $\mathrm{C}_{15} \mathrm{H}_{10} \mathrm{O}_{7}$ & -7.6 & $\begin{array}{l}\text { 1] Electrostatic } \\
\text { Interaction:GLU166 } \\
\text {,HIS163, SER144, } \\
\text { LEU141, ASN142, } \\
\text { HIS41, CYS44, } \\
\text { THR25 2]Van der } \\
\text { Waals Interaction: } \\
\text { MET49 }\end{array}$ & -7.9 & $\begin{array}{l}\text { 1] Electrostatic Interaction: } \\
\text { GLY143, CYS145, MET49, } \\
\text { MET165, GLU166, PHE140, } \\
\text { LEU141, ASN142 2]Van } \\
\text { der Waals Interaction: NIL }\end{array}$ \\
\hline 11 & $\begin{array}{l}\text { Ciprofloxa } \\
\text { cin }\end{array}$ & $\mathrm{C}_{17} \mathrm{H}_{18} \mathrm{FN}_{3} \mathrm{O}_{3}$ & -6.3 & $\begin{array}{l}\text { 1] Electrostatic } \\
\text { Interaction: } \\
\text { HIS41,TYR54, } \\
\text { THR25 2]Van der } \\
\text { Waals } \\
\text { Interaction:MET49, } \\
\text { CYS145 }\end{array}$ & -8.1 & $\begin{array}{l}\text { 1] Electrostatic } \\
\text { Interaction:CYS145, } \\
\text { GLY143,ASP187 2]Van der } \\
\text { Waals Interaction:MET165 }\end{array}$ \\
\hline 12 & $\begin{array}{l}\text { Artemisini } \\
\mathrm{n}\end{array}$ & $\mathrm{C}_{15} \mathrm{H}_{22} \mathrm{O}_{5}$ & -7.8 & $\begin{array}{l}\text { 1] Electrostatic } \\
\text { Interaction:GLU166 } \\
\text {, MET165 2]Van der } \\
\text { Waals } \\
\text { Interaction:CYS145 } \\
\text { HIS41 }\end{array}$ & -7.6 & $\begin{array}{lr}1] & \text { Electrostatic } \\
\text { Interaction:MET49, } & \text { GLu166 } \\
\text { 2]Van der } & \text { Waals } \\
\text { Interaction:CYS145 } & \end{array}$ \\
\hline 13 & $\begin{array}{l}\text { Clindamyc } \\
\text { in }\end{array}$ & $\mathrm{C}_{18} \mathrm{H}_{33} \mathrm{ClN}_{2} \mathrm{O}_{5} \mathrm{~S}$ & -7.8 & $\begin{array}{l}\text { 1] Electrostatic } \\
\text { Interaction:SER144, } \\
\text { HIS163, THR190, } \\
\text { PRO168, LEU167, } \\
\text { GLU166 2]Van der } \\
\text { Waals }\end{array}$ & -9.0 & $\begin{array}{l}\text { 1] Electrostatic Interaction: } \\
\text { MET165 2]Van der Waals } \\
\text { Interaction:MET49, CYS145 }\end{array}$ \\
\hline
\end{tabular}




\begin{tabular}{|c|c|c|c|c|c|c|}
\hline & & & & $\begin{array}{l}\text { Interaction:HIS172, } \\
\text { MET165, }\end{array}$ & & \\
\hline 14 & Quinine & $\mathrm{C}_{20} \mathrm{H}_{24} \mathrm{~N}_{2} \mathrm{O}_{2}$ & -6.9 & $\begin{array}{l}\text { 1] Electrostatic } \\
\text { interaction: } \\
\text { THR190, MET165, } \\
\text { GLU166 2]Van der } \\
\text { waals interaction: } \\
\text { PHE185, PRO168, } \\
\text { HIS164 }\end{array}$ & -8.5 & $\begin{array}{l}\text { 1]Electrostatic interaction: } \\
\text { GLU166 , ASN142, } \\
\text { PHE1402]Van der waals } \\
\text { interaction:MET165, } \\
\text { CYS145 }\end{array}$ \\
\hline
\end{tabular}

The visualization of the various non covalent interactions between compounds and active site residues of 6LU7 (Fig 1a to fig 14b).

*H-Bonds are depicted by Green, Electrostatic is dark yellow, Hydrophobic are represented by pink shades, Halogen interaction by Cyan
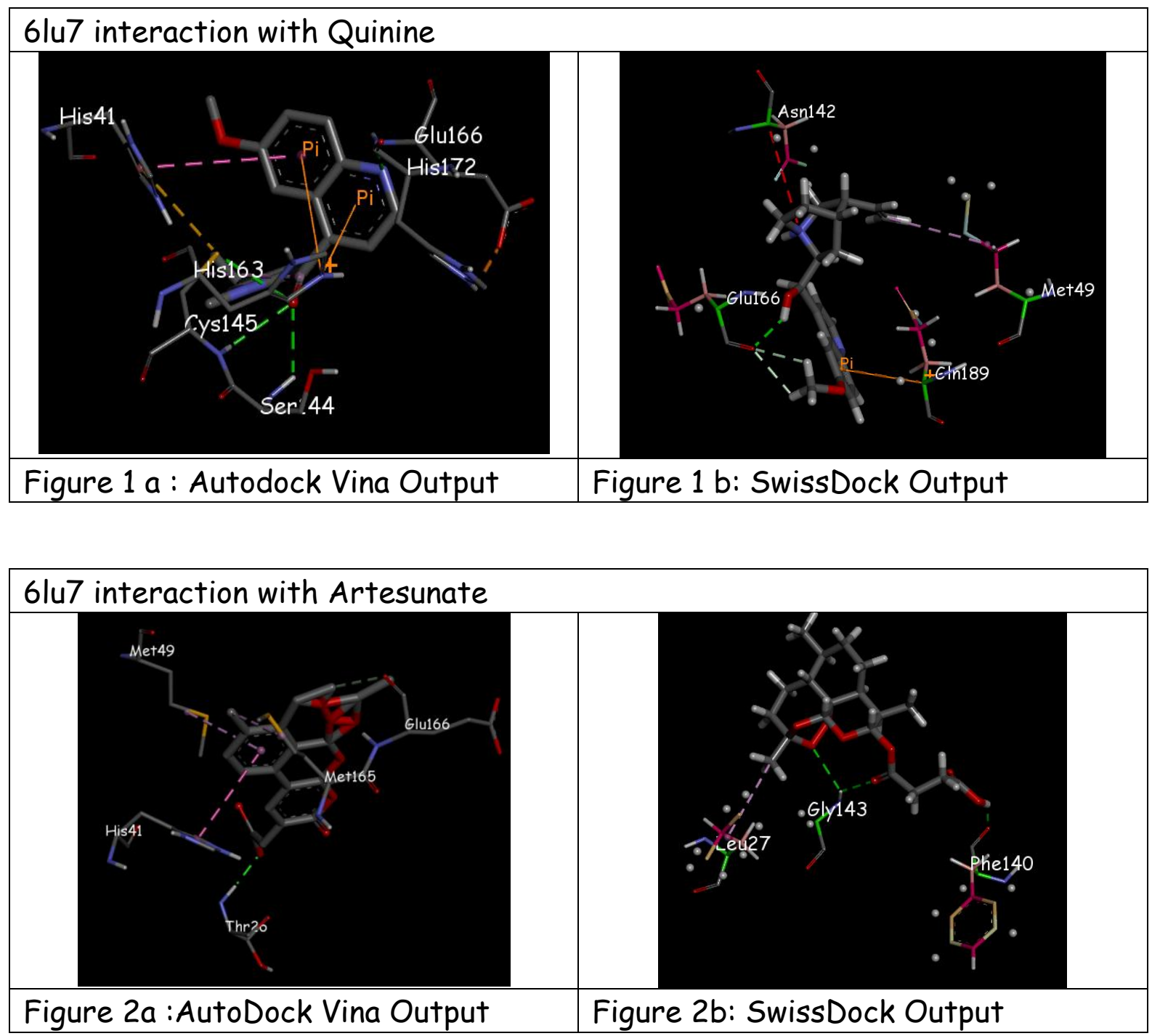

6lu7 interaction with Clotrimazol 

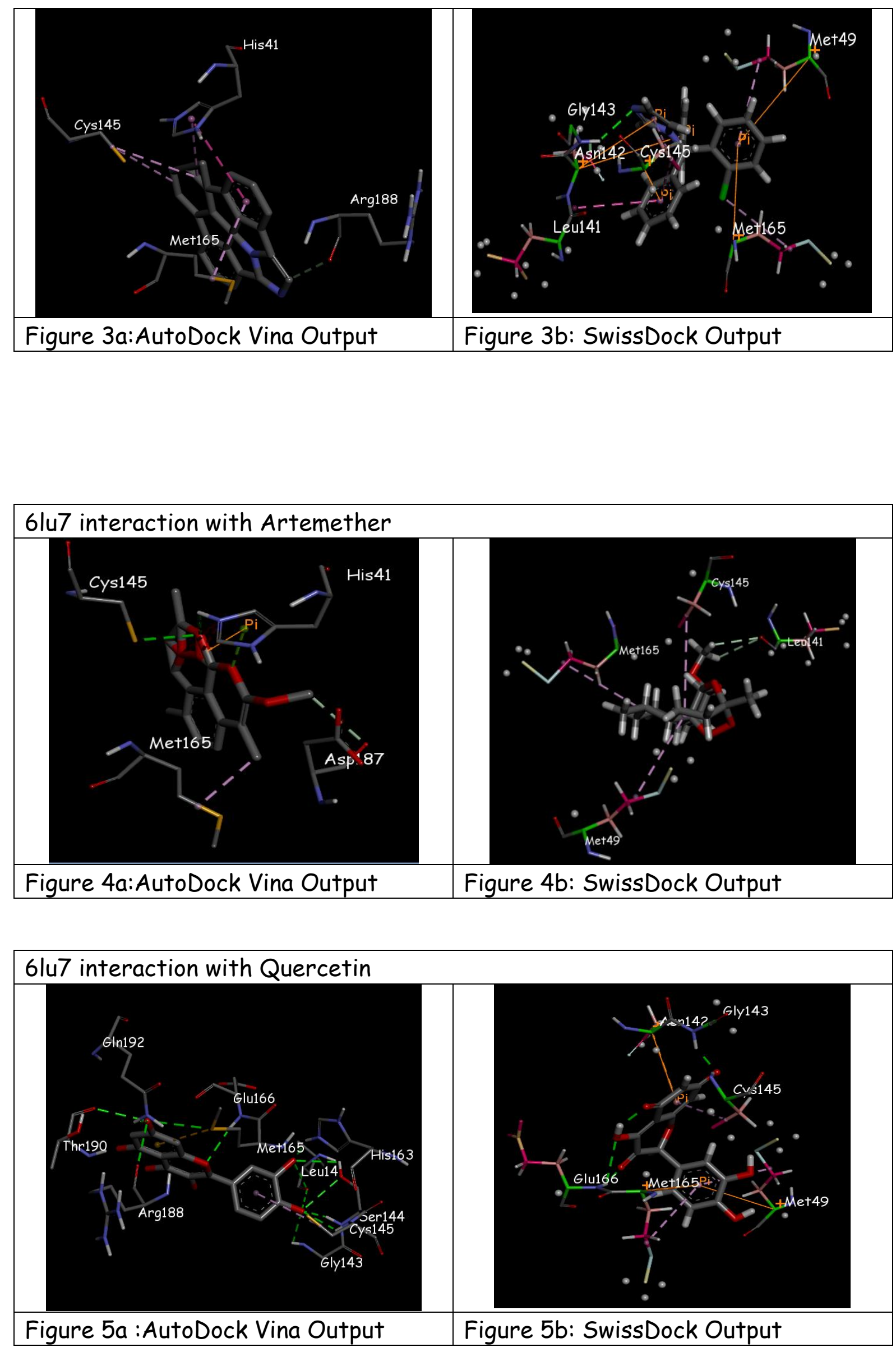

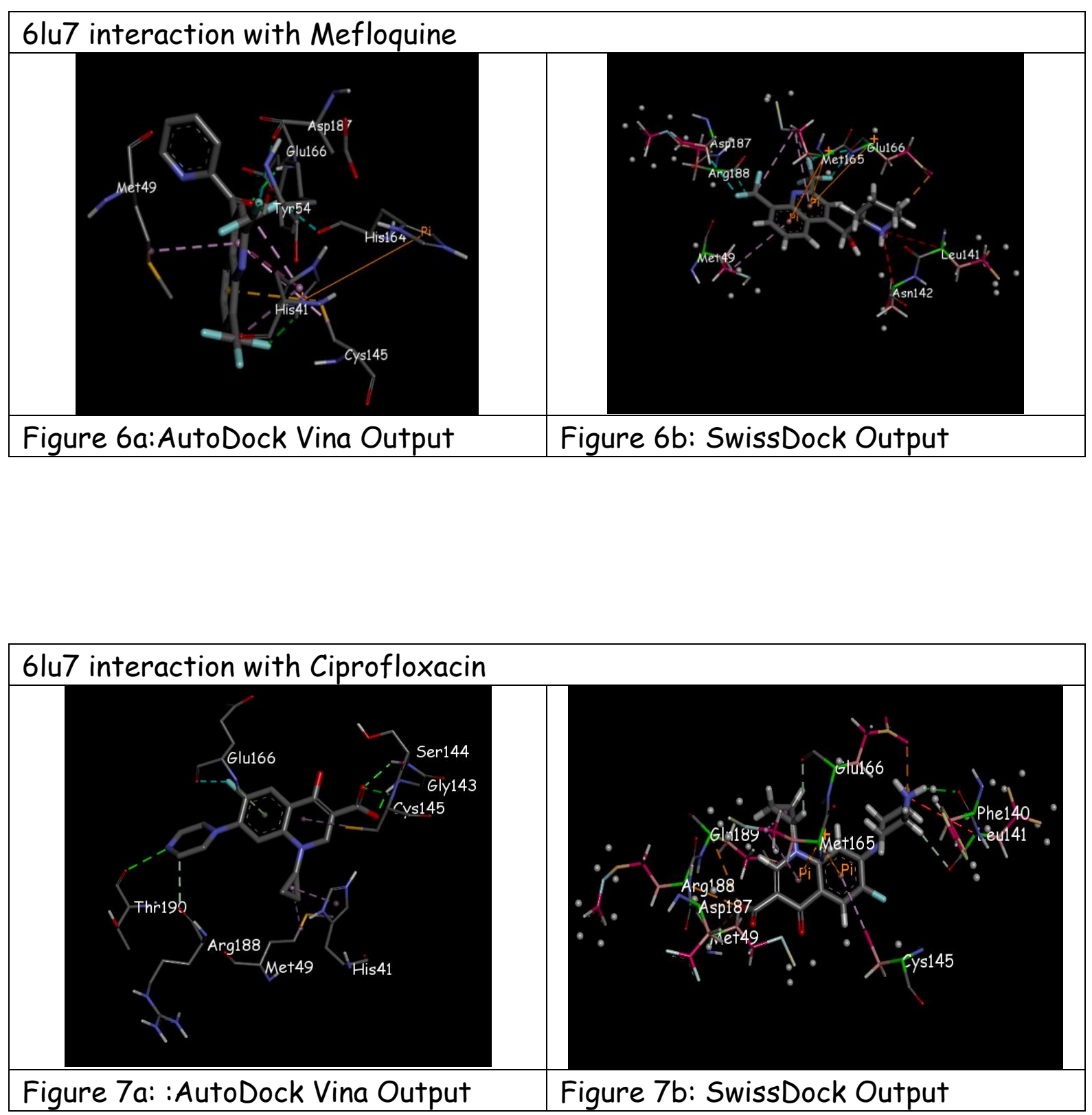

6lu7 interaction with Clindamycin 


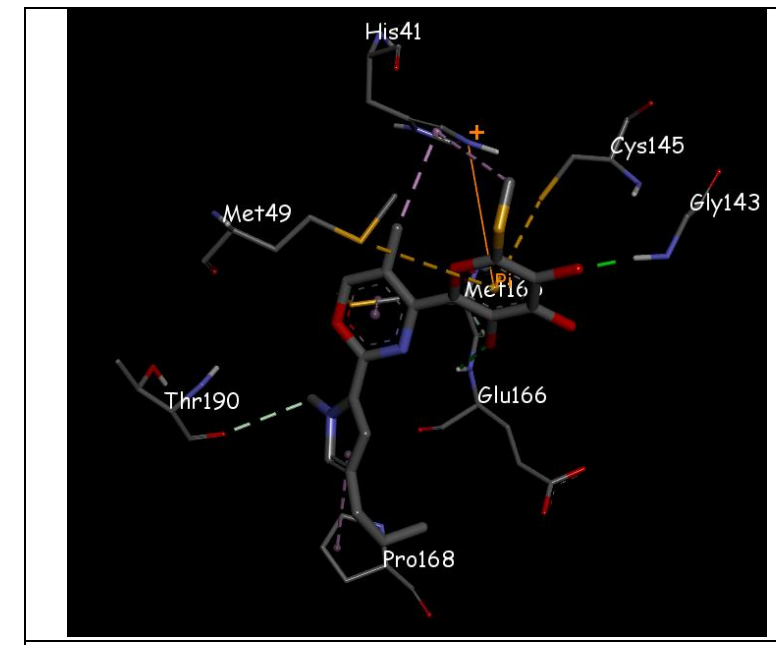

Figure 8a:AutoDock Vina Output

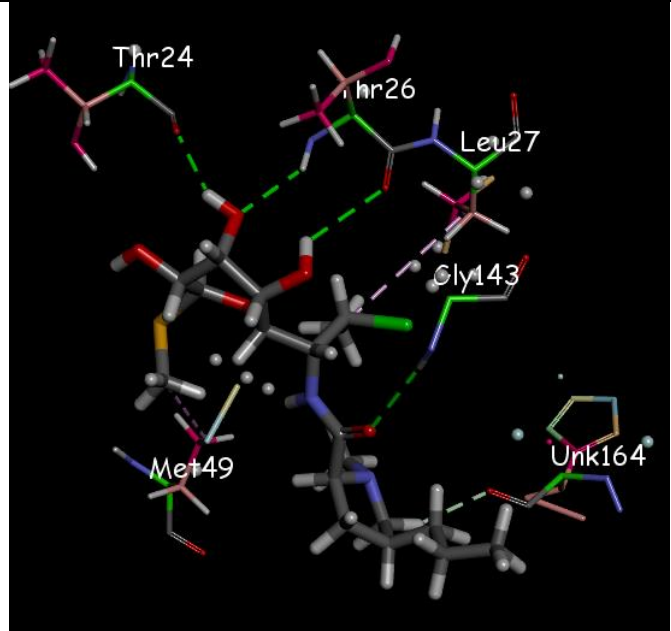

Figure 8b: SwissDock Output

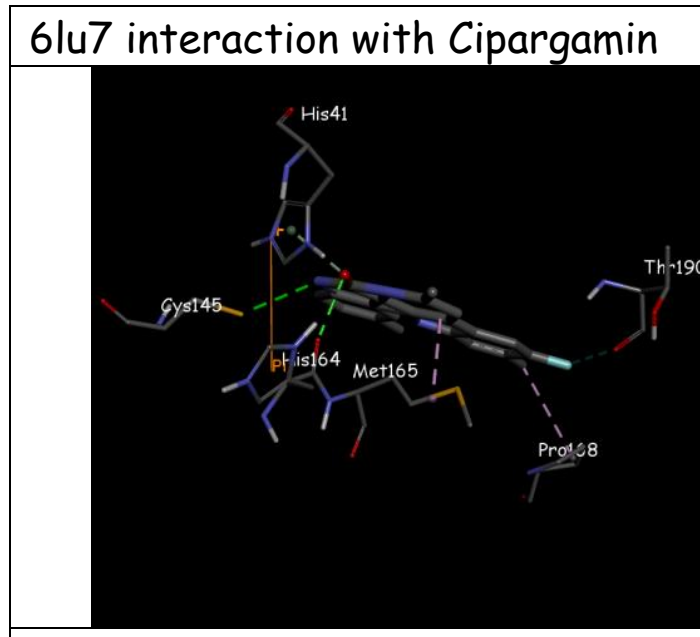

Figure 9a:AutoDock Vina Output

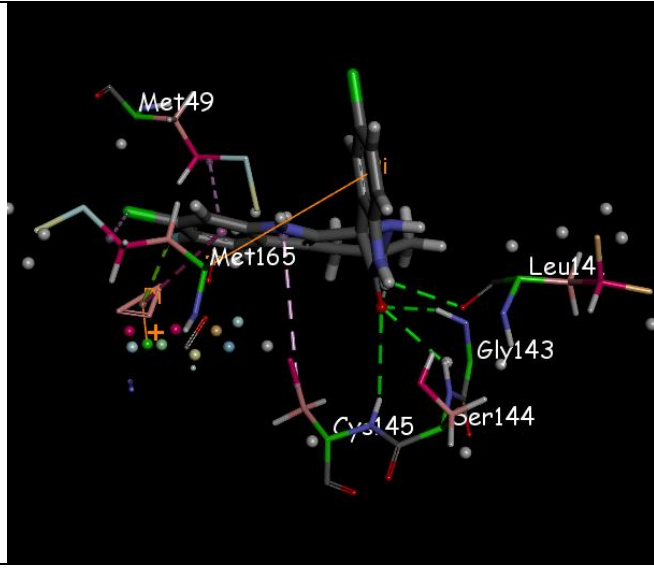

Figure 9b: SwissDock Output

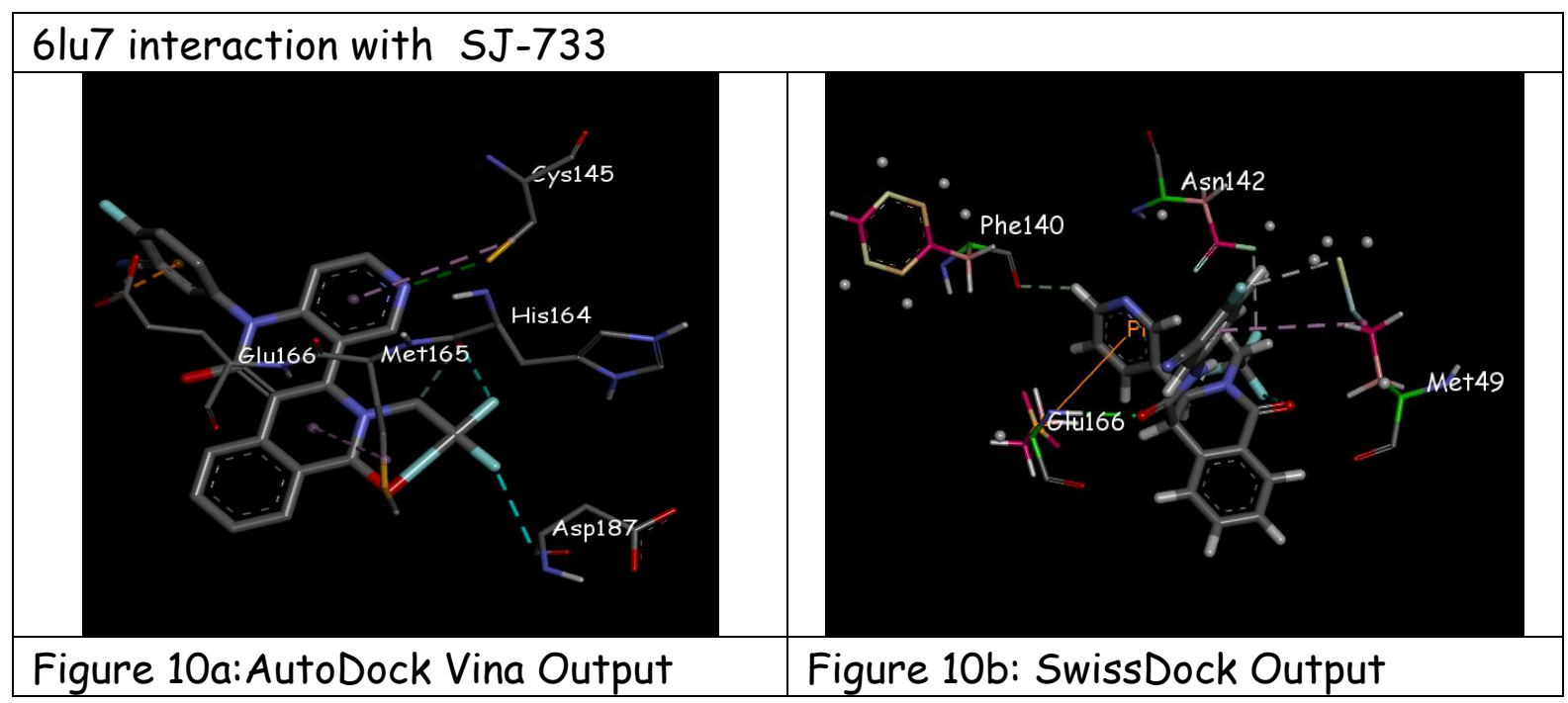

6lu7 interaction with Tafenoquine 


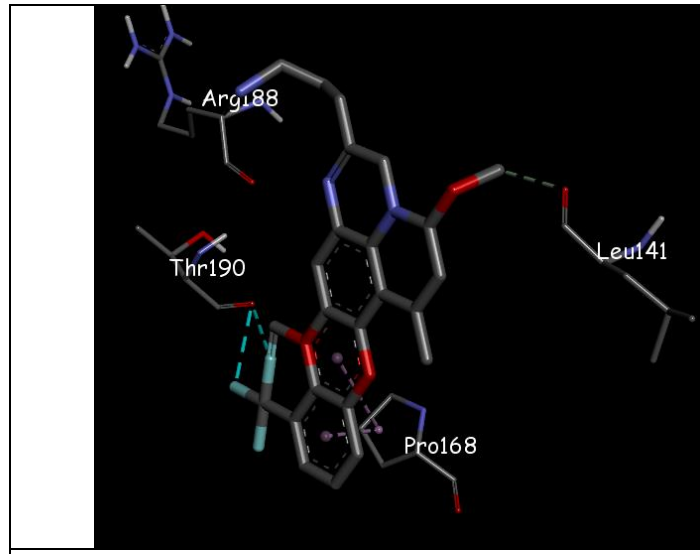

Figure 11a:AutoDock Vina Output

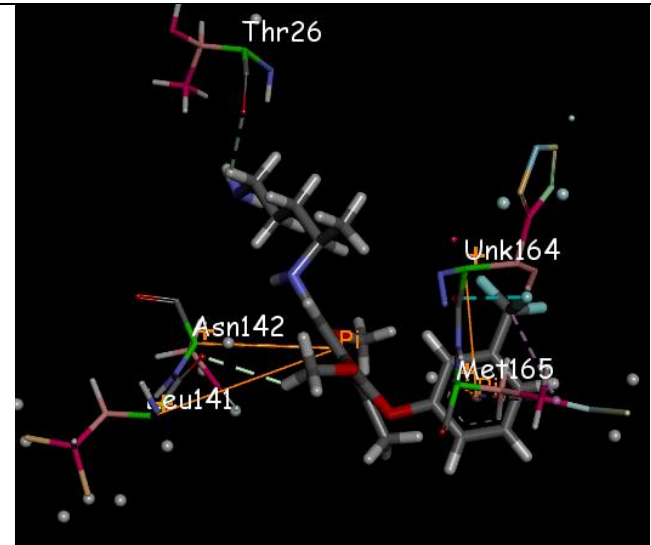

Figure 11b: SwissDock Output
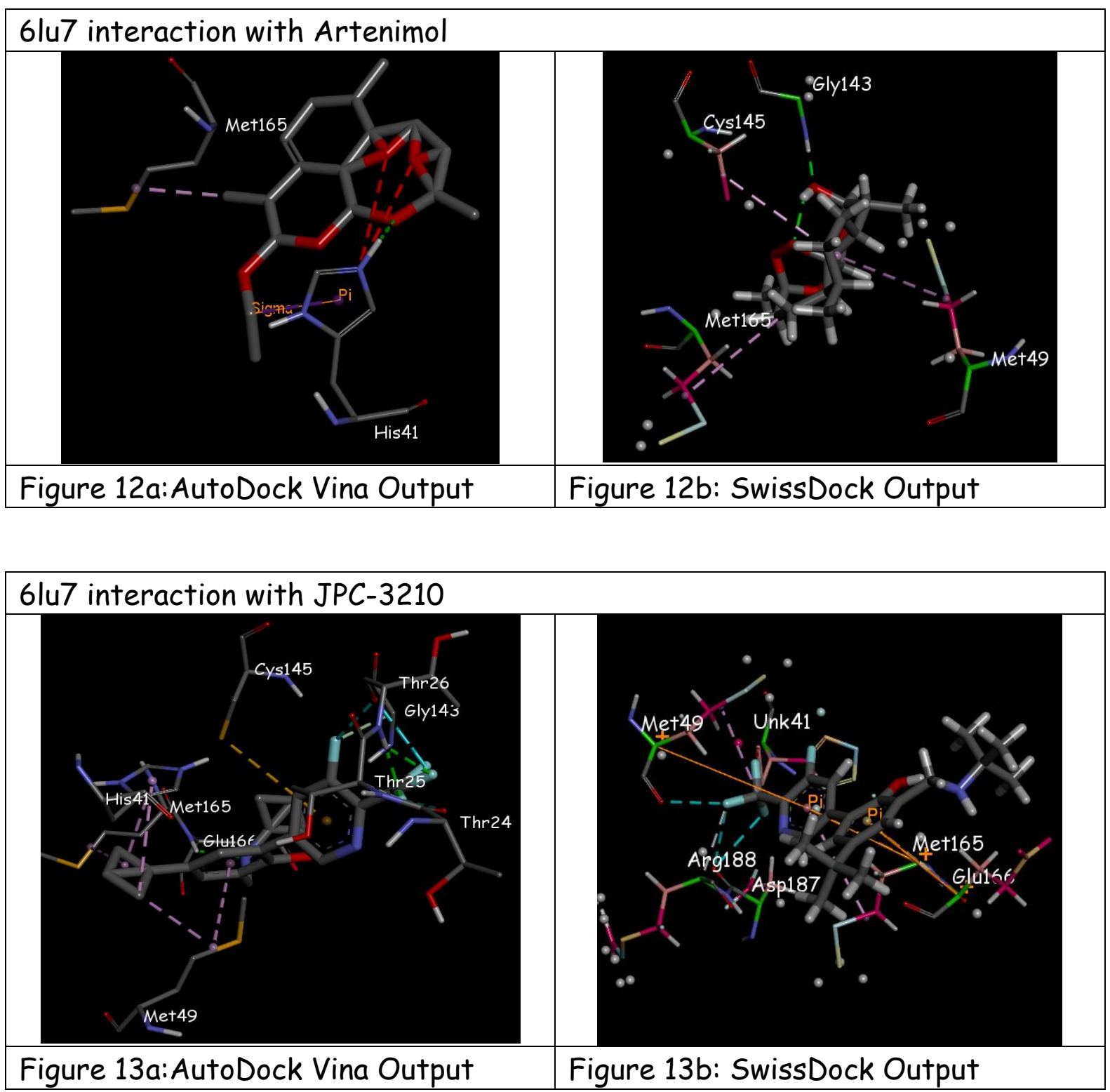

6lu7 interaction with Artemisinin 


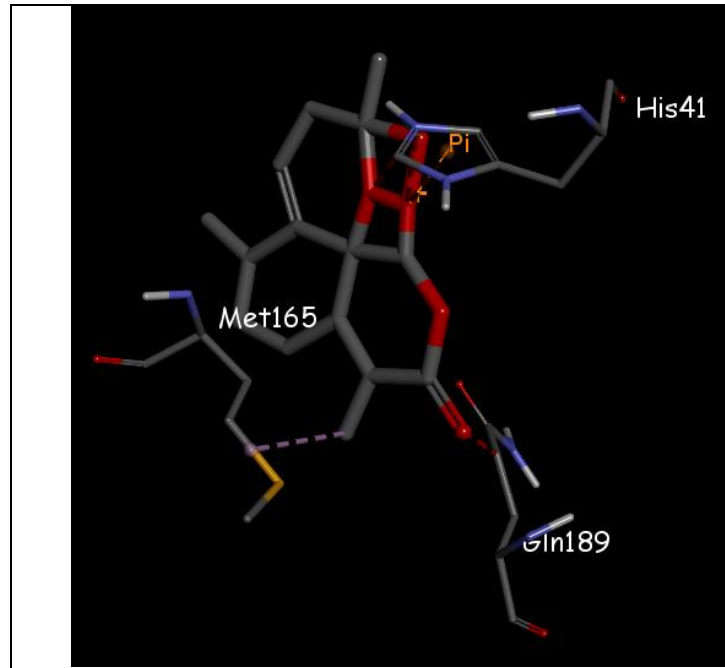

Figure 14a:AutoDock Vina Output

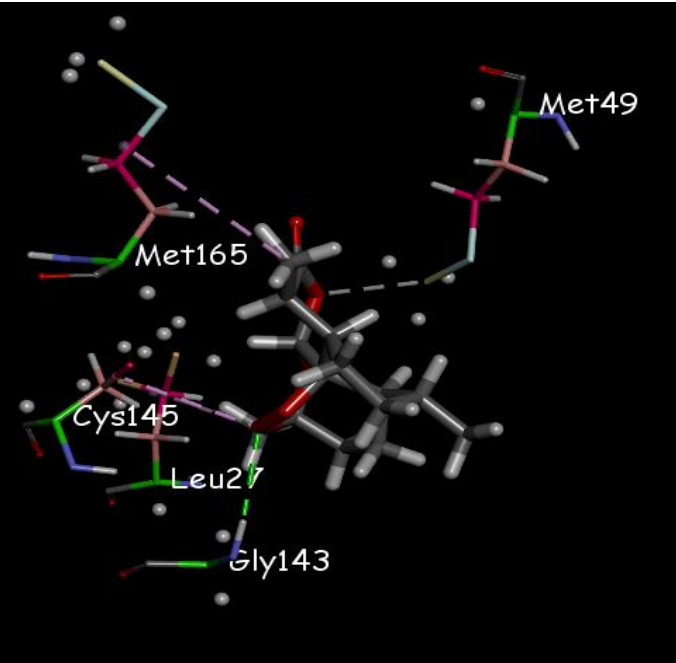

Figure 14b: SwissDock Output

The visualization of the various non covalent interactions between compounds and active site residues of 2 GTB (Fig 15a to fig 28b).

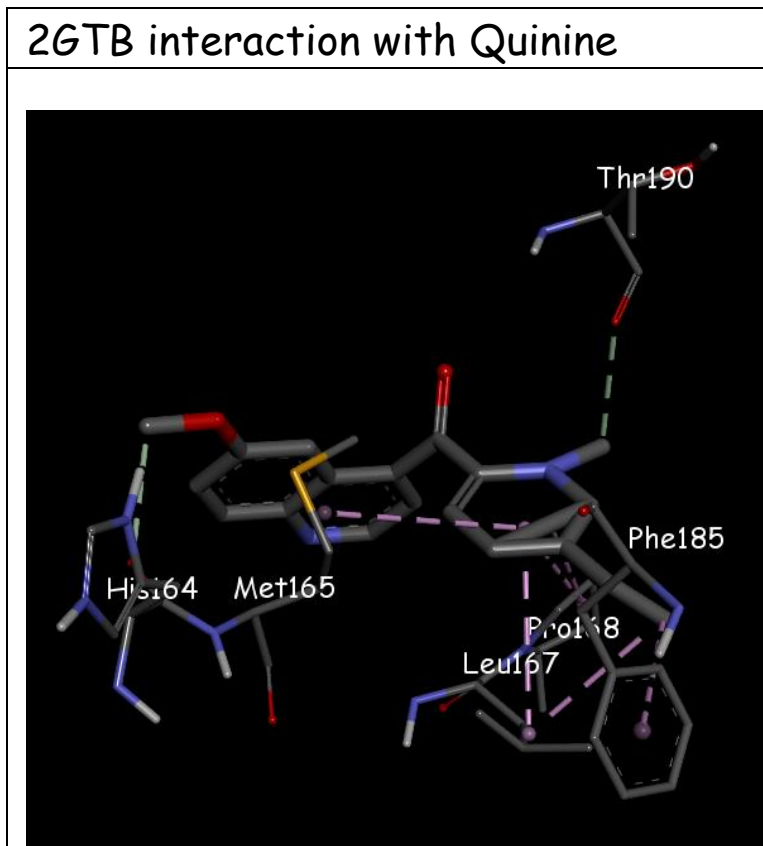

Figure 15a:AutoDock Vina Output

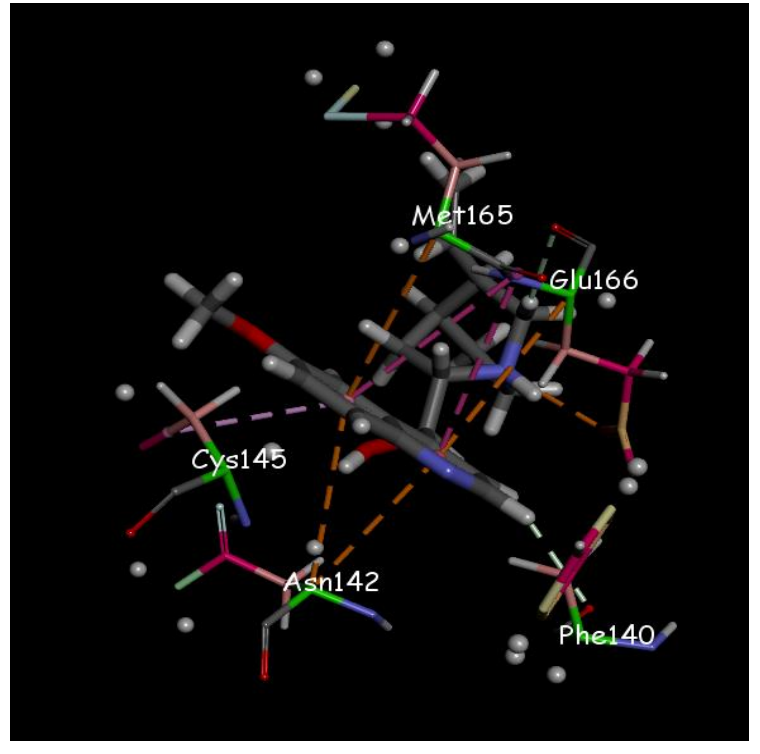

Figure 15b: SwissDock Output 


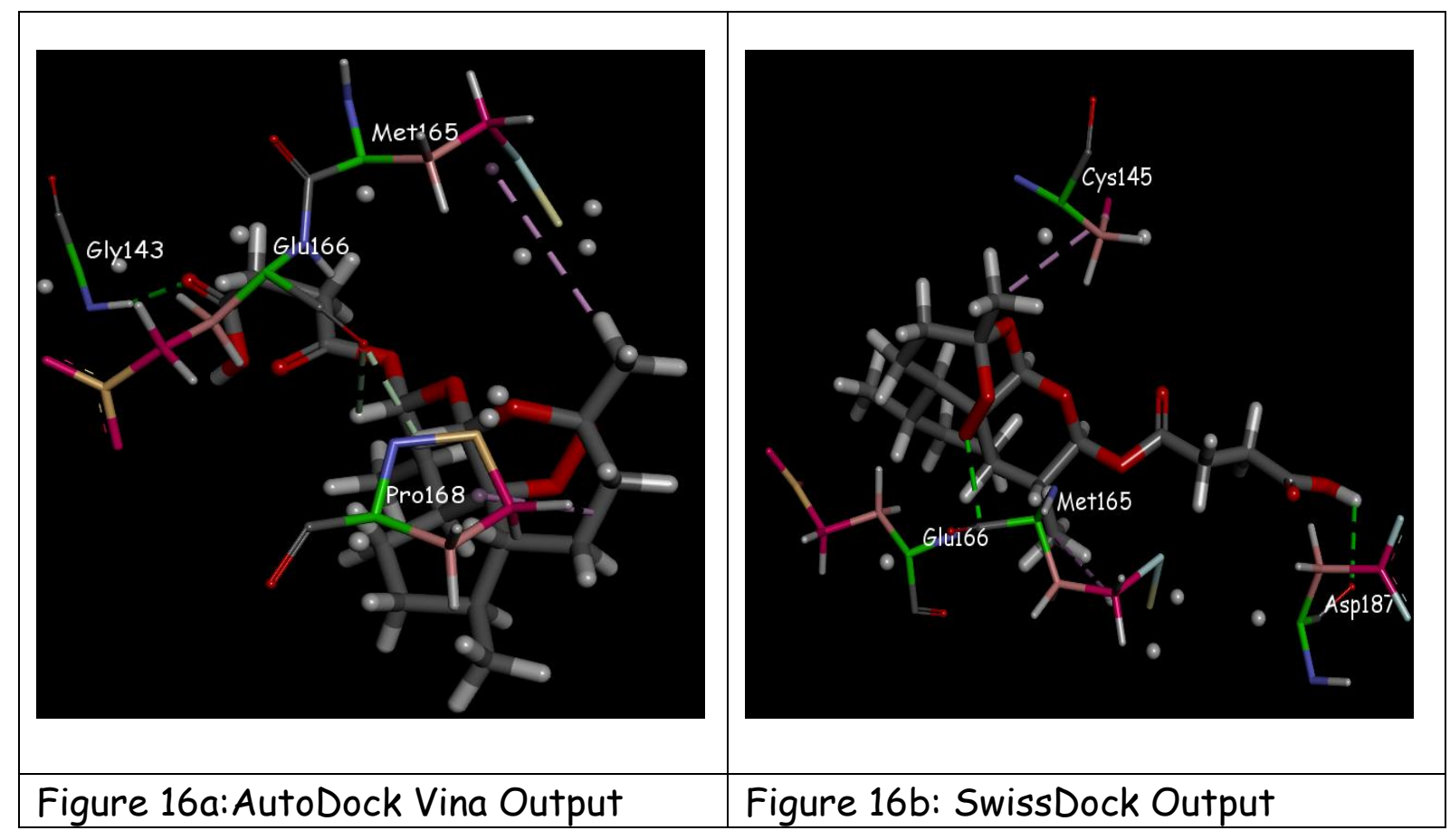

\section{GTB interaction with Clotrimazol}
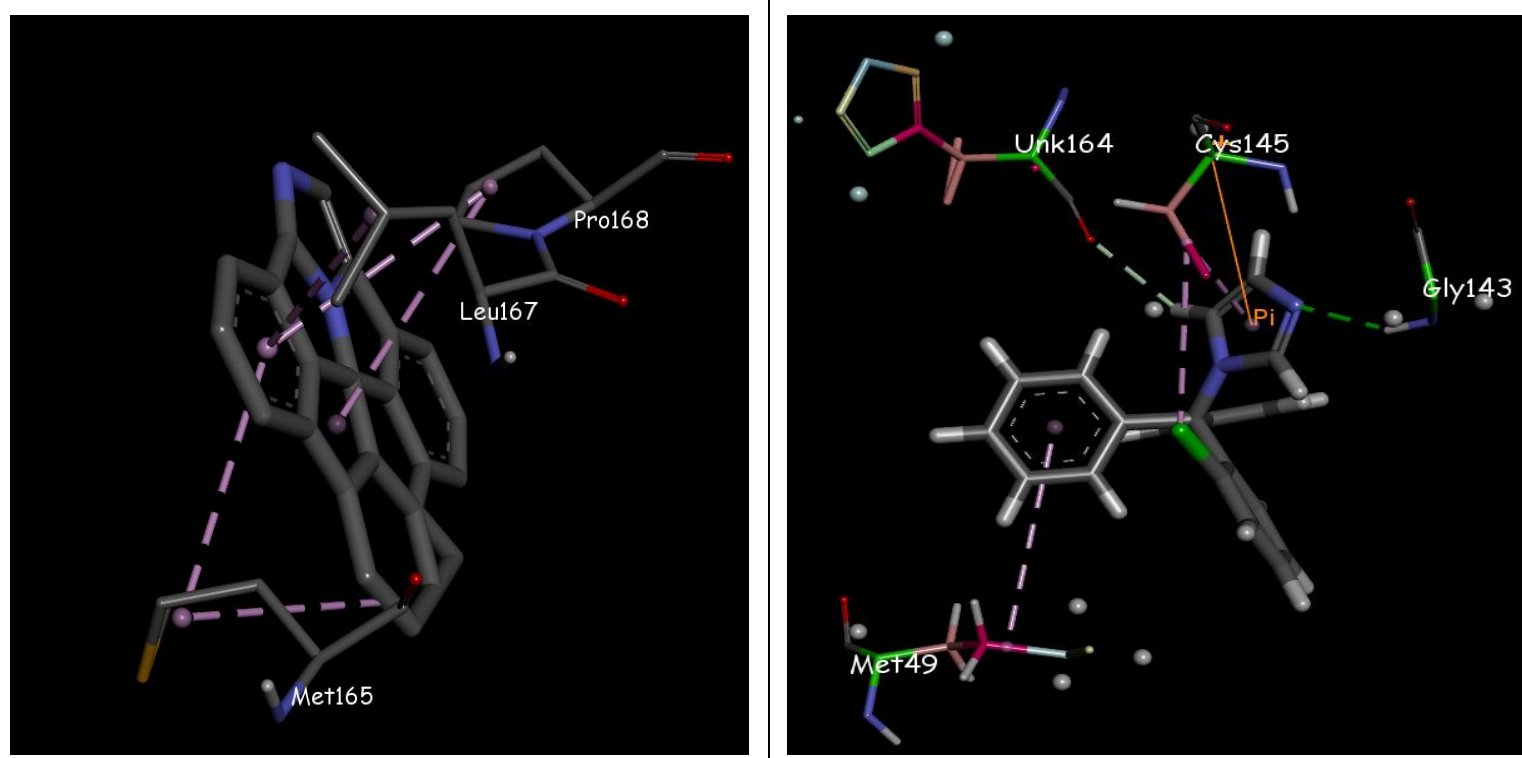

Figure 17a:AutoDock Vina Output

Figure 17b: Swiss Dock Output 

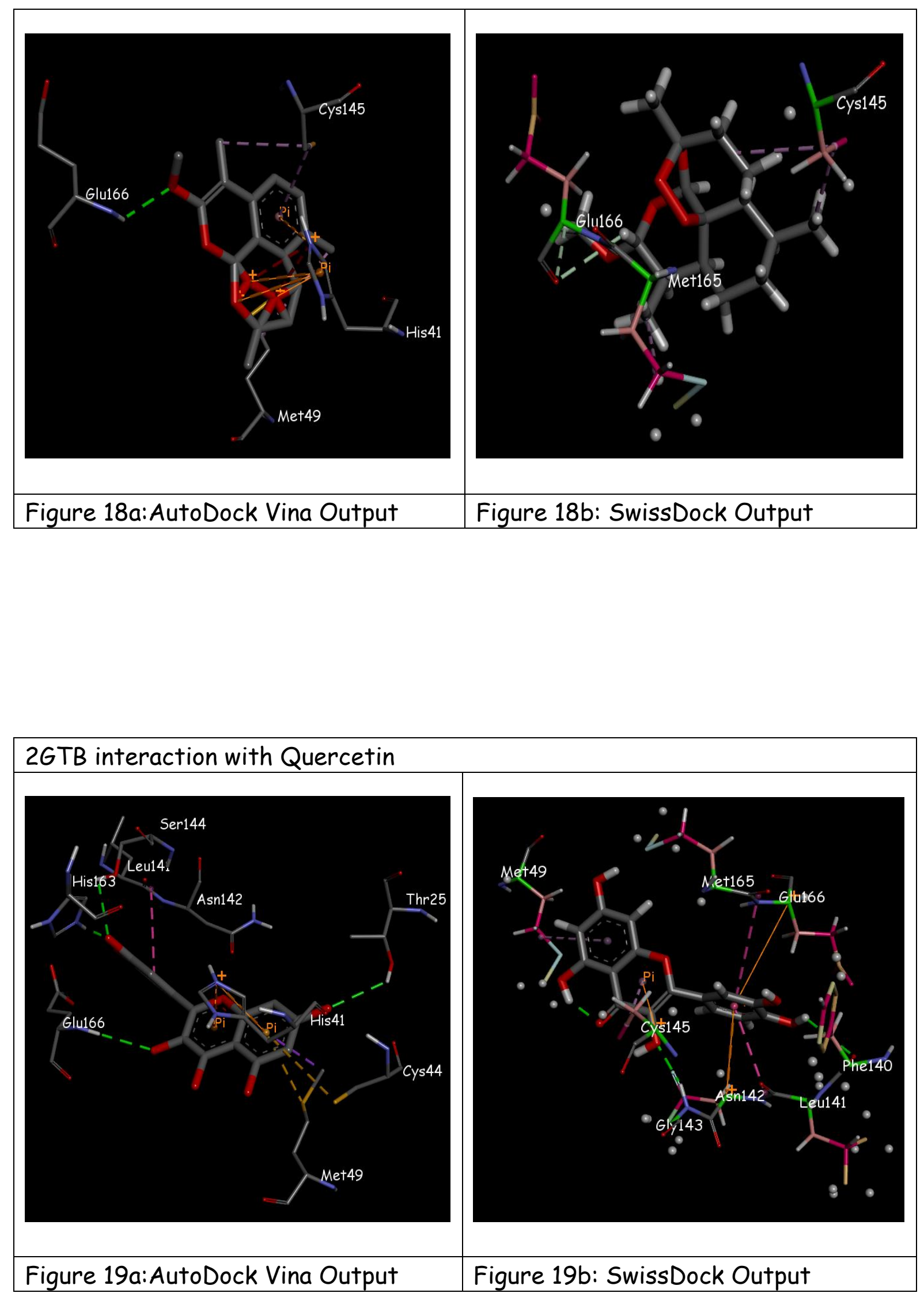

2GTB interaction with Mefloquine 

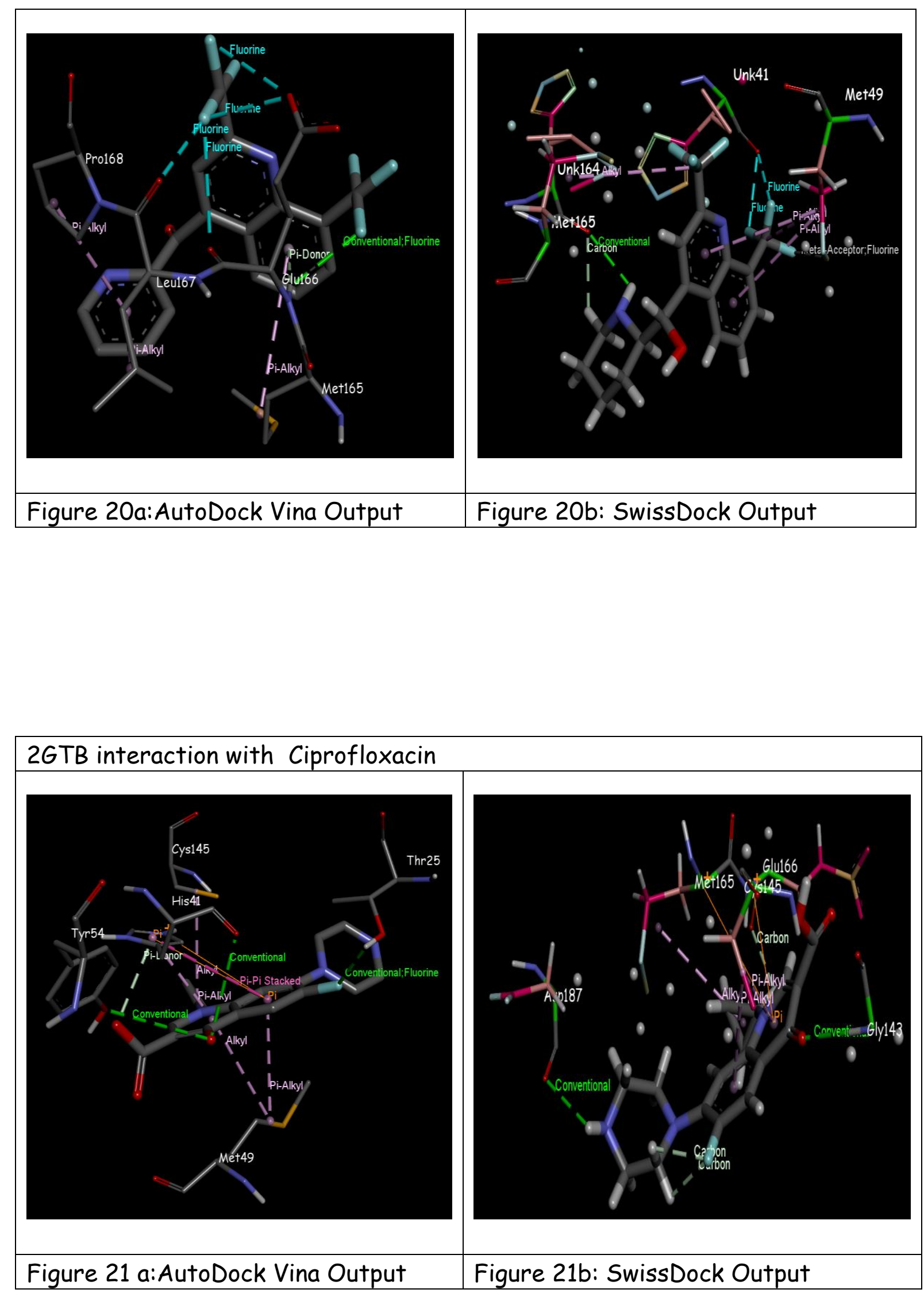

2GTB interaction with Clindamycin 

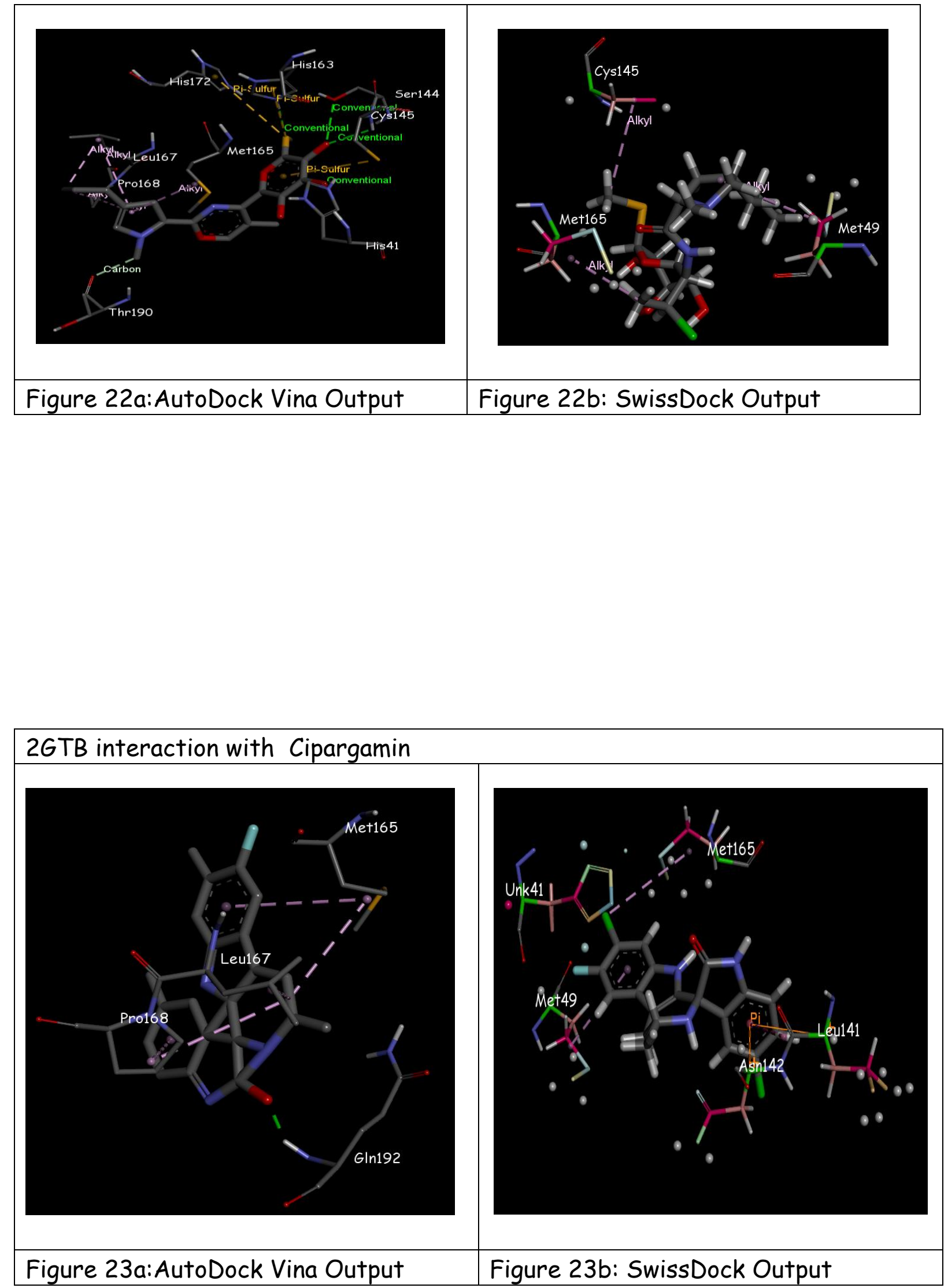

2GTB interaction with SJ-733 

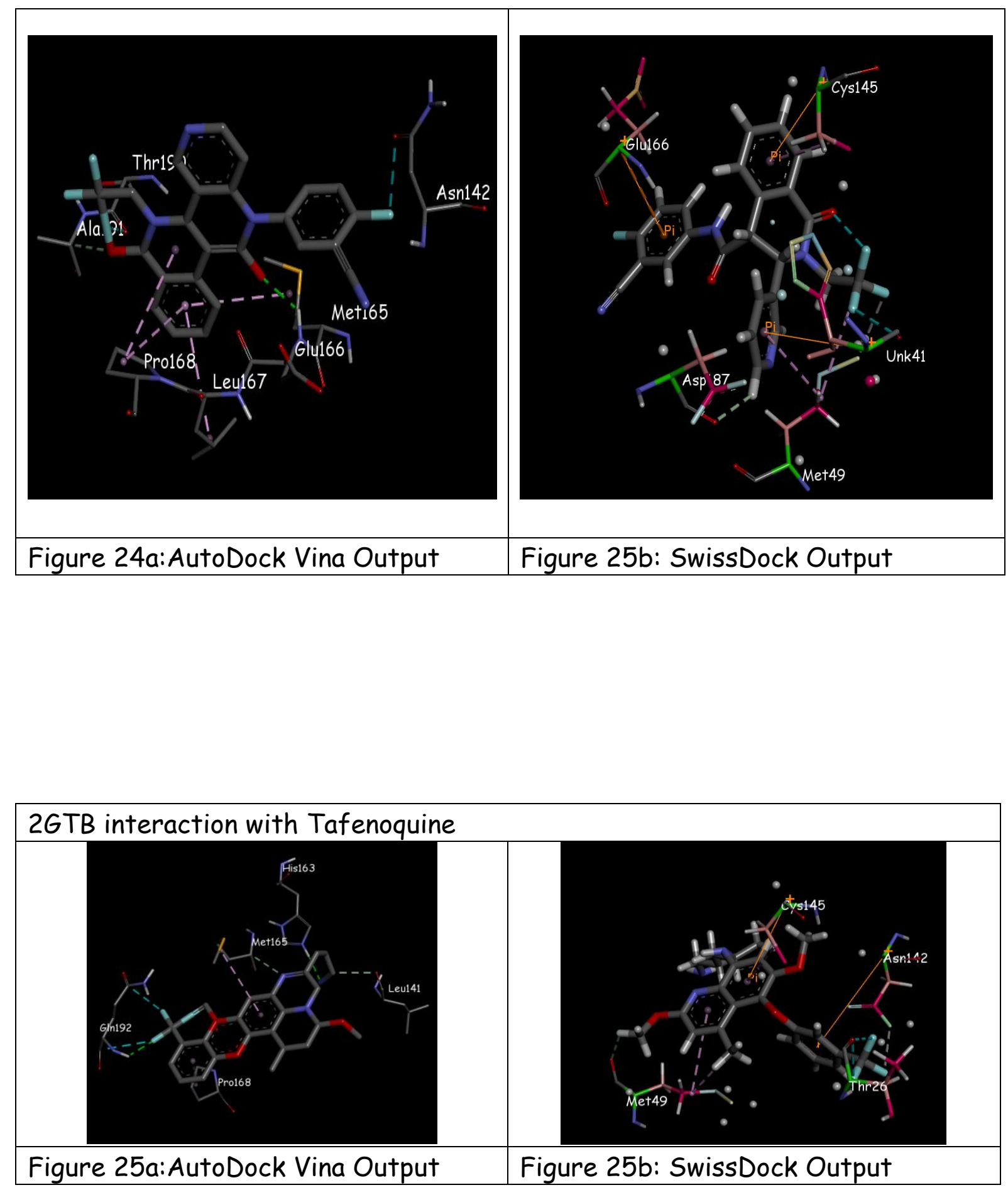

2GTB interaction with Artenimol 

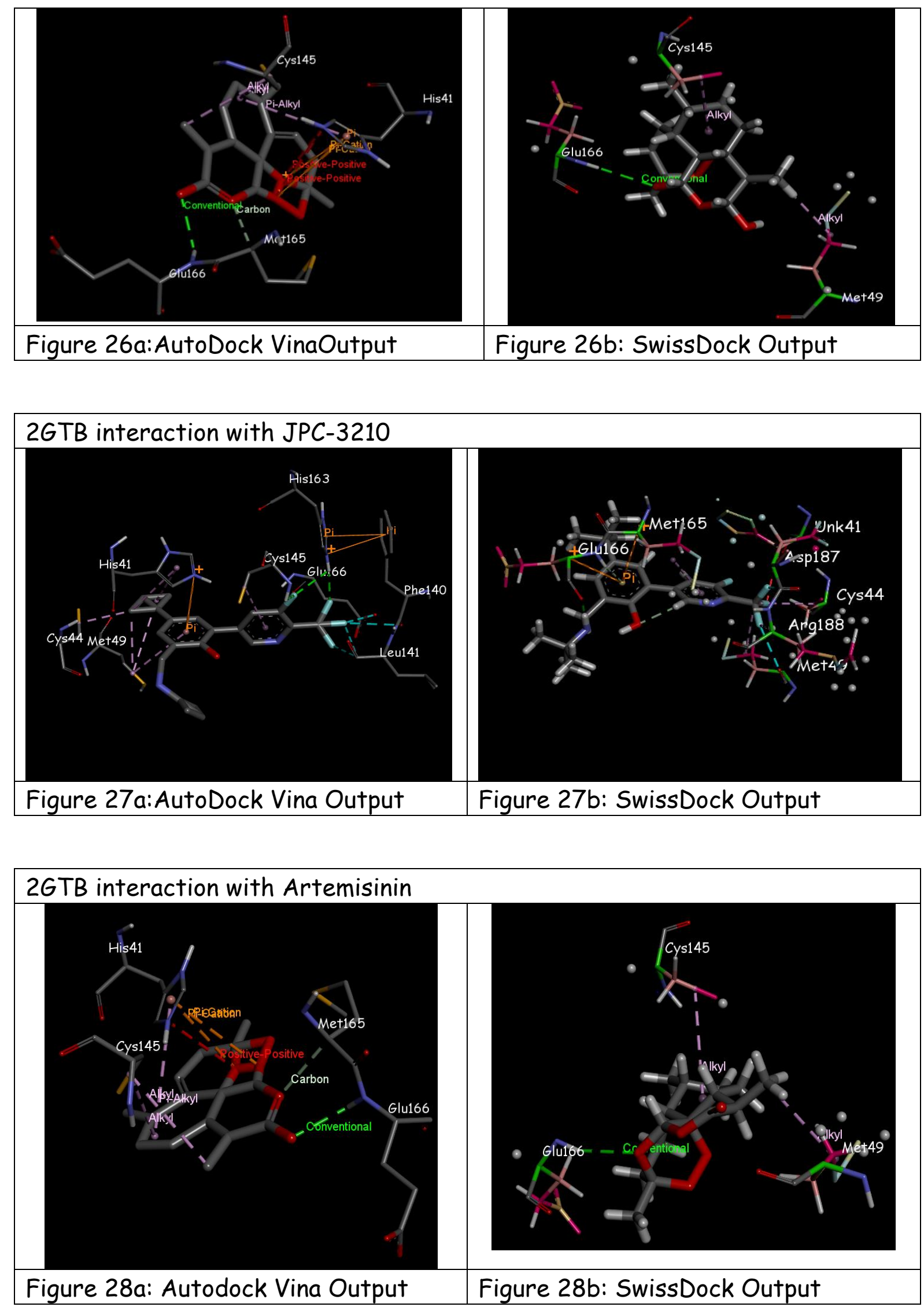


\section{Discussion:}

$\mathrm{CoV}$ infections affect the respiratory, digestive, liver, and central nervous systems of humans and animals (12). this study focused on the most proteases in CoVs (3CLpro/Mpro), especially PDB ID 6LU7, and 2GTB as potential target proteins for COVID-19 treatment 6LU7 is that the Mpro in COVID-19 . that has been structured and repositioned in PDB and has been accessible by the general public since early February 2020. The Mpro of 2019-nCov shares $96 \%$ similarity with the Mpro of the SARS-CoV (13),(14). The Mpro in CoV is important for the proteolytic maturation of the virus and has been examined as a possible target protein to stop the spread of infection by inhibiting the cleavage of the viral polyprotein(15). The invention of the Mpro protease structure in COVID-19 provides an excellent opportunity to spot potential drug candidates for treatment. Proteases represent potential targets for the inhibition of $\mathrm{CoV}$ replication, and therefore the refore the protein sequences of the SARS-CoV Mpro and the 2019-nCoV Mpro are 96\% identical, and therefore the active sites in both proteins remain free from mutations. The Mpro amino acids GLU166, CYS 44, CYS145, SER 144 and MET49 are predicted to play roles in drug interactions (16). The disruption of protease activity can cause various diseases; thus, commonly, host proteases are often used as potential therapeutic targets. In many viruses, proteases play essential roles in viral replication; therefore, proteases are often used as protein targets during the event of antiviral therapeutics (17).

\section{Conclusion:}

In summary, basing on the structural information of clinical effective medicines for 2019$\mathrm{nCoV}$, we have predicted a list of commercial medicines which may function as inhibitors for 2019-nCoV by targeting its main protease Mpro. Compared to Quinine and hydroxycloroquinine, most of these predicted drugs could form more hydrogen bounds with 2019-nCoV Mpro, . The binding pockets of these drugs on Mpro are conserved between SARS-CoV Mpro and 2019-nCoV Mpro, indicating the potential of these drugs to function as inhibitors for other coronaviruses with similar Mpro binding sites and pocket structures.

\section{Acknowledgement:}

Authors like to acknowledge CEO and Medical Director of Bai Jerbai Wadia Hospital for Children for their support and encouragement for the submission of this work.

\section{References:}

1. WHO. Coronavirus disease 2019 ( COVID-19 ). 2020;2019(April).

2. Alfonso J Rodríguez-Morales, Kirsten MacGregor, Sanch Kanagarajah , Dipti Patel PS. "Going global - Travel and the 2019 novel coronavirus,." 2020;(January).

3. Kumar A, Singh A, Shaikh A, Singh R. Chloroquine and hydroxychloroquine in the treatment of COVID-19 with or without diabetes : A systematic search and a narrative review with a special reference to India and other developing countries. 2020;(January).

4. Khaerunnisa S, Kurniawan H, Awaluddin R, Suhartati S. Potential Inhibitor of 
COVID-19 Main Protease ( M pro ) from Several Medicinal Plant Compounds by Molecular Docking Study. 2020;(March):1-14.

5. Wishart DS, Feunang YD, Guo AC, Lo EJ, Marcu A, Grant JR, et al. DrugBank 5.0: A major update to the DrugBank database for 2018. Nucleic Acids Res. 2018;46(D1):D1074-82.

6. Giménez BG, Santos MS, Ferrarini M, Dos Santos Fernandes JP. Evaluation of blockbuster drugs under the rule-of-five. Pharmazie. 2010;65(2):148-52.

7. Lipinski CA. Lead- and drug-like compounds: The rule-of-five revolution. Drug Discov Today Technol. 2004;1(4):337-41.

8. Ritchie TJ, Ertl P, Lewis R. The graphical representation of ADME-related molecule properties for medicinal chemists. Drug Discov Today [Internet]. 2011;16(1-2):65-72. Available from: http://dx.doi.org/10.1016/j.drudis.2010.11.002

9. Morris G.M., Dallakyan S. AutoDock - AutoDock. Citeseer. 2013;1(1).

10. Forli W, Halliday S, Belew R, Olson A. AutoDock Version 4.2. Citeseer. 2012;

11. Zoete V, Michielin O. SwissDock, a protein-small molecule docking web service based on EADock DSS. 2011;39(November 2010):270-7.

12. Xu J, Zhao S, Teng T, Abdalla AE, Zhu W, Xie L, et al. Systematic comparison of two animal-to-human transmitted human coronaviruses: SARS-CoV-2 and SARS-CoV. Vol. 12, Viruses. 2020.

13. Zhavoronkov A, Aladinskiy V, Zhebrak A, Zagribelnyy B, Terentiev V, Bezrukov DS, et al. Potential 2019-nCoV 3C-like protease inhibitors designed using generative deep learning approaches Potential COVID-19 3C-like protease inhibitors designed using generative deep learning approaches. ChemRxiv Prepr. 2020;307(2):E1.

14. Yinon M Bar-On, Avi Flamholz, Rob Phillips RM. SARS-CoV-2 (COVID-19) by the numbers. Available from: https://elifesciences.org/articles/57309

15. Chia-Nan Chen,,Coney P.C.Lin,*, Kuo-Kuei Huang1, Wei-Cheng Chen1, Hsin-Pang Hsieh1 P-HL and JT-AH. Inhibition of SARS-CoV 3C-like Protease Activity by Theaflavin-3,3_-digallate (TF3). Adv Access Publ. 2005;2(2):209-15.

16. Liu X, Wang XJ. Potential inhibitors against 2019-nCoV coronavirus M protease from clinically approved medicines. J Genet Genomics. 2020;119-21.

17. Chang KO, Kim Y, Lovell S, Rathnayake AD, Groutas WC. Antiviral drug discovery: Norovirus proteases and development of inhibitors. Viruses. 2019;11(2):1-14. 